\title{
Career Options for Scientists
}

\author{
Richard Sever and Kaaren Janssen \\ Cold Spring Harbor Laboratory, New York
}

\begin{abstract}
Most PhD students in the biological sciences will not go on to become academics. For these individuals, choosing the best career path can be difficult. Fortunately, there are many options that allow them to take advantage of skills they hone during graduate and postdoctoral work.
\end{abstract}

\begin{abstract}
A $\mathrm{PhD}$ and postdoctoral work were once considered to be a training route to a permanent academic position, a journey that would culminate in a tenure-track position and, ultimately, stability as a principal investigator at a university or research institute. Some might falter along the way or rethink their career, but most scientists expected to tread the same path that their predecessors trod to tenure.

This is no longer the reality for most science graduates. Universities are awarding more $\mathrm{PhDs}$ than ever before, and more than half of these individuals will become postdocs (Cyranoski et al. 2011). However, there has been no equivalent increase in the number of tenured faculty positions at universities and research institutes (Fig. 1). In the 1960s, most scientists who obtained a $\mathrm{PhD}$ could expect a permanent academic position. In contrast, only approximately one in four PhDs in the United States now translate to a tenure-track position, and even fewer will ultimately result in tenure (National Institutes of Health 2012). In other words, the majority of $\mathrm{PhD}$ students will never obtain the tenured post for which many initially believed they were being trained.
\end{abstract}

Fortunately, there is now increasing recognition within academia that career options once labeled as "alternative" are not in fact the alternative but the norm. Most mentors now also accept that many of their scientific progeny will pursue such options-not because they fail on the road to tenure but because they actively choose careers that offer a different experience and the chance to develop other skills. A PhD is still training for a scientific career but not one as narrowly defined as a research faculty position.

Turning off the track to tenure remains a daunting prospect, however, and it can be hard to find out about the different career options available. We therefore gathered the perspectives of a group of scientifically trained individuals who have had great success in transitioning to a variety of different professions, and these will be appearing in forthcoming issues of Cold Spring Harbor Perspectives in Biology, starting perhaps appropriately with science writing (Pearson 2017). The experiences of the contributors range from jobs that in some respects resemble traditional scientific positions, such as teaching, grant administration, and core facility management, to jobs that require additional formal training, such as patent

Editors: Kaaren Janssen and Richard Sever

Additional Perspectives on Career Options for Biomedical Scientists available at www.cshperspectives.org

Copyright (C) 2017 Cold Spring Harbor Laboratory Press; all rights reserved; doi: 10.1101/cshperspect.a032755

Cite this article as Cold Spring Harb Perspect Biol 2017;9:a032755 
R. Sever and K. Janssen

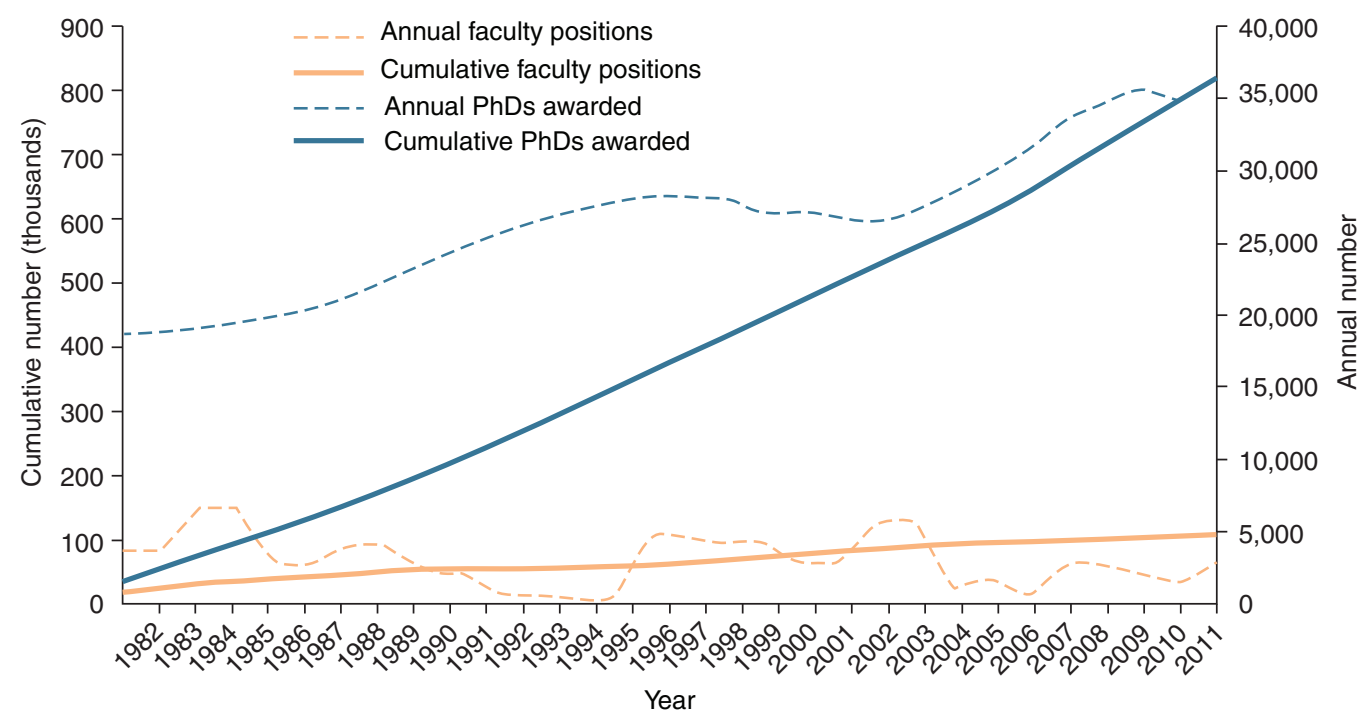

Figure 1. The increase in the number of PhDs awarded in science and engineering in the United States compared with changes in the number of faculty positions over the same period. (Reproduced from Schillebeeckx et al. 2013, with permission from Macmillan Publishers Ltd.)

law, or, in cases such as management consultancy, can take one away from science entirely. In all of these professions, individuals who hold $\mathrm{PhDs}$ in biomedical sciences are common and, in many instances, a $\mathrm{PhD}$ and postdoctoral experience are advantageous if not essential. Nevertheless, it is worth paying close attention to the specifics of each case. Staying on for a postdoc could be an advantage if you wish to work as a journal editor, for example, and it keeps your options open, but it will put you 3-8 years behind many of your new peers if ultimately what you want is to be a journalist.

Some of these careers-teaching in liberal arts colleges, core facility management, and academic administration-resemble traditional academic careers in many respects but have a different primary emphasis: the interests of students, a facility, or a department or educational institute as a whole. For a foundation or government post, the missions and constituencies also differ. In patent law and management consulting, the interests are clients; in start-ups, they are customers and investors. This changes the nature of the work significantly. In medical communication, science journalism, and scien- tific publishing, the focus is instead readers. Superficially similar, these careers all involve writing about science, but the purpose and audience are different in each case; so too are the skills required.

Despite the differences among these professions, however, several common themes emerge. Perhaps most importantly, it is clear that the skills developed in the course of a $\mathrm{PhD} /$ postdoc are not wasted: They are directly applicable to other careers. Critical thinking, problem solving, and the ability to sift through and make sense of a variety of data are as essential to a patent lawyer or a management consultant as they are to a principal investigator. Digesting complex scientific concepts, identifying flaws in the logic of a study, and communicating them effectively are as critical a part of the job of a journal editor as a research professor. And rigorous evaluation of proposed lines of scientific enquiry is just as important to a grant-giving organization as it is to the head of a lab. Job candidates should always remember these parallels. In most cases, when scientists leave the bench and apply for their first jobs in new professions, they have little or no demonstrable di- 
rect experience. But if they can convince interviewers that their skills are transferable, they may have a foot in the door.

Another common theme is that these different career trajectories are neither second rate nor second choice. Teaching science at a liberal arts college, for example, is not a consolation for lack of success in research (a strong research program is often essential) but a choice for people who wish to put more time into teaching. Working for a journal or scientific society requires you to increase the breadth of your scientific knowledge, not reduce it. And no one should imagine that mastering the law in addition to molecular biology and genomics makes being a patent attorney an easy way out. All of the professions covered in these forthcoming articles are extremely competitive, with tens to hundreds of applicants for every entry-level position. Those charged with selecting from this rich pool are disinclined to consider people who appear simply to be looking for an easier alternative to life at the bench. For people displaying genuine interest and ability, however, there are opportunities to join organizations that typically provide excellent training and working environments staffed by kindred spirits who have lost none of their love of science.

What should be most encouraging to young scientists is how exciting and rewarding all these careers are. One hears this time and time again. Those who have chosen a different scientific path delight in their work and rarely express any regret.

\section{REFERENCES}

Cyranoski D, Gilbert N, Ledford H, Nayar A, Yahia M. 2011. Education: The PhD factory. Nature 472: 276-279.

National Institutes of Health. 2012. Biomedical Research Workforce Working Group Report https://acd.od.nih .gov/biomedical_research_wgreport.pdf/.

Pearson H. 2017. Careers in science journalism and writing. Cold Spring Harb Perspect Biol 9: a032961.

Schillebeeckx M, Maricque B, Lewis C. 2013. The missing piece to changing the university culture. Nat Biotechnol 31: $938-941$. 


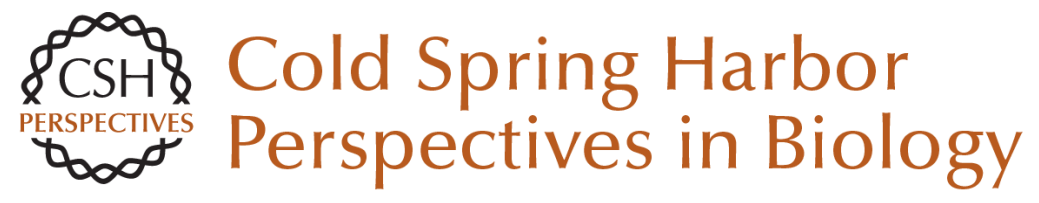

\section{Career Options for Scientists}

Richard Sever and Kaaren Janssen

Cold Spring Harb Perspect Biol 2017; doi: 10.1101/cshperspect.a032755

\section{Subject Collection Career Options for Biomedical Scientists}

\section{Careers in Science Publishing} John R. Inglis

Medical Communications: The "Write" Career

Path for You? Yfke Hager

At the Crossroads of Science and Society: Careers in Science Policy Amy P. Patterson, Mary E. Groesch, Allan C. Shipp, et al.

A Career in Patent Law: At the Cutting Edge of Science, but Not at the Bench Salim Mamajiwalla

Careers in Science and Grant Administration: View from the National Institutes of Health Marion Zatz and Sherry Dupere

Careers at Biotech Start-Ups and in

\section{Entrepreneurship} Susan Froshauer

Careers in Science Journalism and Writing Helen Pearson
Careers in Academic Administration Lydia Villa-Komaroff

Working for a Scientific Society Martin Frank

A Career for Life Scientists in Management Consulting Rodney W. Zemmel

Careers in Core Facility Management Claire M. Brown

Leaving the Bench and Finding Your Foundation John E. Spiro

A Career at a Small Liberal Arts College Jennifer Punt

Career Options for Scientists

Richard Sever and Kaaren Janssen

For additional articles in this collection, see http://cshperspectives.cshlp.org/cgi/collection/

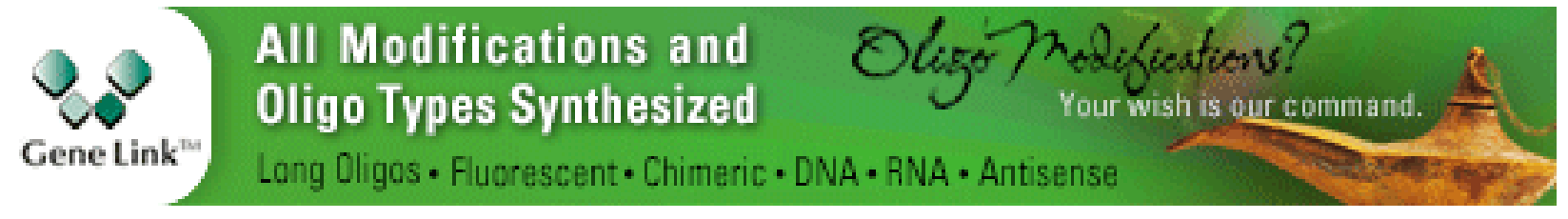

Copyright @ 2017 Cold Spring Harbor Laboratory Press; all rights reserved 